AMPLIACIONES DE AMBITO

\title{
Presencia de Ephydatia fluviatilis (Porifera: Spongillidae) en Costa Rica
}

\author{
(Rec. 5-IV-1994. Acep. 14-VII-1994)
}

Key words: Porifera, Spongillidae, freshwater sponges.

Los registros de esponjas de agua dulce en Centroamérica son escasos (Poirrier 1982) por falta de estudios. Las especies conocidas son Eunapius fragilis en Guatemala (Meek 1905); Trochospongilla leidyi, T. horrida y E. carteri en Panamá (Poirrier 1990); Anheteromeyenia ryderi en Belize (Poirrier 1977); Spongilla alba y Ephydatia fluviatilis en El Salvador (Poirrier 1989). Para Costa Rica no hay registro de ninguna especie; sin embargo, en muestreos en la Provincia de Guanacaste se ha encontrado $R a$ diospongilla y E. fluviatilis (M. Poirrier, com. pers.).

Ephydatia fluviatilis (Linnaeus, 1759), Porifera : Spongillidae.

\section{Nuevo ámbito geográfico: Costa Rica.}

Ambito anterior: El Salvador (Poirrier, 1989).

En Junio de 1991 se colectó macrófitas emergentes (Polygonum punctatum, y Echinochloa pyramidalis) en el Refugio Nacional de Vida Silvestre Caño Negro en Costa Rica, $\left(10^{\circ} 51^{\prime}-10^{\circ} 54^{\prime} \mathrm{N}\right.$; 84⒋ $\left.48^{\prime}-84^{\circ} 54 \mathrm{~W}\right)$. Se depositaron en un tanque de asbesto con agua y se mantuvieron a $27.0^{\circ} \pm 0.5 \mathrm{c}$ y fotoperíodo de 10:14. Posiblemente sobre las plantas venían gémulas de E. fluviatilis ya que aproximadamente a los dos meses se habían desarrollado masas blancas que alcanzaron hasta $20 \mathrm{~cm}$ de diámetro. $\mathrm{La}$ especie es cosmopolita y común en aguas de áreas costeras o con influencia marina, pero tambien se ha encontrado en pantanos o en humedales que se secan durante el verano (Poirrier 1974), la última característica es típica del Refugio de Vida Silvestre de Caño Negro, donde el nivel de agua baja marcadamente en los meses de época seca (noviembre a marzo). Los especímenes estan depositados en el Museo de la Universidad de Costa Rica, en el catálogo Esponjas $N^{\circ} 164-\mathrm{UCR}$.

\section{AGRADECIMIENTOS}

Agradezco a C. Volkmer-Ribeiro su valiosa ayuda en la identificación de la especie.

\section{REFERENCIAS}

Poirrier, M.A. 1974. Ecomorphic variation in gemmoscleres of Ephydatia fluviatilis Linnaeus (Porifera:Spongillidae) with comments upon its sustematics and ecology. Hydrobiologia. 44:337-347.

Poirrier, M.A. 1982. Porifera, p. 59-61. In SH. Hurlbert,. \& A. Villalobos-Figueroa (eds.). Aquatic Biota of Mexico, Central America and the West Indies, San Diego State University, San Diego, California.

Poirrier, M.A. 1990. Freshwater sponges (Porifera:Spongillidae) from Panama. Hydrobiologia 194: 203-20-5.

Poirrier, M.A. \& S. Trabanino 1989. Freshwater sponges (Porifera: Spongillidae) from lake Ilopango, El Salvador, with observations on spicule malformation in Spongilla alba. Trans. Am. Microsc. Soc. 108:211-214. 